\title{
Avaliação de objetos de aprendizagem sobre o sistema digestório com base nos princípios da Teoria Cognitiva de Aprendizagem Multimídia
}

\author{
Evaluation of learning objects on the digestive system \\ based on the principles of Cognitive Theory \\ of Multimedia Learning (CTML)
}

\author{
Rosiney Rocha Almeida ${ }^{1}$ • Andréa Carla Leite Chaves ${ }^{2}$. \\ Francisco Ângelo Coutinho ${ }^{3}$. Carlos Fernando de Araújo Júnior ${ }^{1}$
}

\begin{abstract}
Resumo: Esta pesquisa se propõe a avaliar objetos de aprendizagem (OAs) digitais relacionados à temática "sistema digestório" a partir de alguns princípios da Teoria Cognitiva de Aprendizagem Multimídia (TCAM). Para a análise, selecionaram-se OAs de fácil acesso, livres de custos ao usuário final, apresentados em língua portuguesa e adequados a alunos do Ensino Médio. Observou-se que a maioria dos modelos instrucionais não levou em consideração os princípios dessa teoria na sua construção e produção. Os resultados obtidos neste estudo indicam que, em relação ao conteúdo "sistema digestório", existe a necessidade de que o planejamento e a construção de OAs sejam orientados por princípios que visem tornar o uso dos recursos multimídia mais eficientes, do ponto de vista cognitivo.
\end{abstract}

Palavras-chave: Avaliação. Objeto de aprendizagem. Digestão. Ensino de biologia. Multimídia. TCAM.

\begin{abstract}
This research aims to assess Learning Objects (OA) digitally related to the theme "digestive system" based on some principles of Cognitive Theory of Multimedia Learning (CTML) Mayer (2005). OA was selected for its easy access, zero cost for the end user, presentation in Portuguese language and appropriateness for middle level students. It was observed that most of these instructional models did not give much emphasis to the principles of this theory in their construction and production. The results of this study indicate that, in relation to the "digestive system" content, there is a need for the planning and construction of $\mathrm{OA}$ to be guided by principles and criteria aiming to make the use of multimedia resources more efficient, and able to make the necessary adjustments and corrections so they can meet the principles of CTML satisfactorily.
\end{abstract}

Keywords: Evaluation. Learning objects. Digestion. Biology teaching. Multimedia. CTML.

\footnotetext{
${ }^{1}$ Programa de Pós-Graduação em Ensino de Ciências e Matemática, Universidade Cruzeiro do Sul, Avenida Jabaquara, 2286, Mirandópolis, CEP 04046-400, São Paulo, SP, Brasil. E-mail: <rrrosyy@yahoo.com.br> ${ }^{2}$ Pontifícia Universidade Católica (PUC) Minas, Belo Horizonte, MG, Brasil.

Departamento de Métodos e Técnicas de Ensino, Faculdade de Educação, Universidade Federal de Minas Gerais (UFMG), Belo Horizonte, MG, Brasil.
} 


\section{Introdução}

Tavares (2007) assevera que ambientes multimídia podem propiciar situações que facilitam a construção de significados, na medida em que oferecem, ao aprendiz, ferramentas poderosas, as quais ele pode utilizar numa atividade individual e colaborativa. Para o autor, a informática educativa pode se colocar como uma ferramenta inclusiva ao estender, a um número maior de pessoas, a possibilidade de conseguir visualizar e abranger fenômenos naturais, como é o caso da digestão. Esse entendimento, antes das tecnologias digitais, seria reservado apenas aos estudantes com capacidade de abstração.

No estudo do sistema digestório, pelas características inerentes aos aspectos biológicos do conteúdo, a utilização de objetos de aprendizagem (OAs), sob as formas de animação, simulação ou vídeo, torna o processo da digestão naturalmente complexo, mais próximo do "real" e "mais significativo para o aluno". O uso de OAs possibilita, ainda, uma compreensão detalhada da estrutura e do funcionamento do sistema digestório difícil de ser obtida, por exemplo, com a utilização de um texto ou uma imagem estática do livro didático.

É consenso, entre diversos autores, a necessidade de realizar uma avaliação para fazer a escolha dos OAs apropriados para um determinado processo de ensino e aprendizagem. (BOFF; REATEGUI, 2005; CAMPOS; ROCHA, 1993; ROMERO; ANDRADE; PIETROCOLA, 2009; SOUZA; PEQUENO; CASTRO FILHO, 2006). Todos concordam que os professores devem dedicar uma atenção inicial e criteriosa à avaliação dos OAs, a fim de garantir o melhor aproveitamento desses nas práticas pedagógicas.

Atualmente, vários estudos discutem modelos de produção e avaliação de OAs que visem maximizar sua qualidade pedagógica. Existem diversas metodologias de avaliação de softwares educativos que realizam suas análises focando em fatores distintos (SOUZA; PEQUENO; CASTRO FILHO, 2006), inexistindo, dessa forma, modelos de padronização desses métodos avaliativos. Como os OAs são, na sua maioria, objetos multimídias, consideramos prudente e adequado que nos apoiemos no conceito de aprendizagem multimídia para fazer a avaliação de OAs. Tal conceito, para Mayer (2001), significa aprendizagem por meio de palavras e imagens.

Portanto, a proposta deste trabalho consiste em avaliar OAs digitais relacionados à temática: sistema digestório a partir de alguns princípios da Teoria Cognitiva de Aprendizagem Multimídia (TCAM), de Mayer (2005).

\section{A Teoria Cognitiva da Aprendizagem Multimídia (TCAM)}

O conceito de aprendizagem multimídia (Multimedia Learning), de acordo com Mayer (2001), é a aprendizagem por meio de palavras e imagens. Segundo o referido autor, as palavras incluem o discurso falado e a parte escrita, enquanto as imagens podem ser estáticas (ilustrações e fotos) ou dinâmicas (animações e vídeos). Porém, a simples adição de figuras e palavras ao material instrucional não garante a aprendizagem. Existem condições de adição de palavras e imagens que devem ser utilizadas para garantir a aprendizagem (MAYER, 2005). Assim, o princípio multimídia enuncia que as pessoas aprendem mais com o uso de imagens e palavras, do que somente com o uso de um ou de outro. A multimídia pode, então, ser compreendida como uma combinação de múltiplos recursos técnicos, cujo propósito é apresentar a informação 
desejada em múltiplos formatos, por meio de múltiplas modalidades sensoriais (SCHNOTZ; LOWE, 2003).

Para Amador e Carneiro (1999), a imagem possui funções que vão além do seu papel ilustrativo. Essa concepção está de acordo com os estudos de Renovato et al. (2009, p. 2) quando dizem que "a linguagem imagética produz e reproduz informações e conhecimentos, pois veicula discursos, significados e intenções". Pesquisadores de ensino de ciências têm afirmado que há uma necessidade urgente de se aprender a "ler" as imagens, portanto, existe a urgência de uma "alfabetização visual” (KRESS; VAN LEEUWEN, 2001).

Segundo Santos e Tarouco (2007), o uso de representações não verbais e verbais amplia a compreensão dos estudantes; e os recursos multimídia e com interatividade são considerados, por professores, como uma forma de motivar os alunos, gerando uma aprendizagem mais eficaz. Embora o uso de recursos multimídias possa contribuir para a aprendizagem, Schnotz e Lowe (2003) afirmam ser um erro pressupor que ambientes de aprendizagem ricos nesses recursos resultem em um processamento cognitivo extensivo e na criação de estruturas e conhecimento elaborados. Ou seja, a utilização da multimídia deve estar alinhada à capacidade cognitiva dos alunos e ao conteúdo a ser ensinado.

Baseado nessas premissas, estudar meios que descrevam os caminhos de como se aprende melhor utilizando ambas, palavras e imagens, constitui o principal objetivo da Teoria Cognitiva de Aprendizagem Multimídia (MAYER, 2005). O problema está em para quem, como, quando e em que sequência se devem utilizar imagens e palavras de forma a alcançar melhores resultados no aprendizado.

Ao mesmo tempo, é importante compreender os mecanismos que são efetuados pelo aluno para a recepção da informação, sua veiculação pelas áreas sensoriais e encefálicas que o fazem ter a compreensão do que é informado. A pesquisa, para essas e outras questões, resultou em muitas respostas, permitindo o desenvolvimento de uma série de princípios. Esses princípios, em conjunto, correspondem à TCAM; e devem ser empregados na construção de modelos instrucionais que, bem projetados, podem levar a melhores resultados do que as práticas tradicionais de ensino.

\section{A TCAM e o processo de ensino e aprendizagem}

Quando se recebe uma informação multimídia via imagens, palavras narradas ou textuais, animações, filmes, dentre outros meios de comunicação, cria-se um modelo mental sobre a informação, indicando sua compreensão, que é então armazenada na memória de longo prazo para posterior utilização. Os mecanismos utilizados pelo aprendiz para se chegar a esse modelo mental e suas implicações no processo de construção do conhecimento são o tema de estudo da TCAM.

"A TCAM tem uma preocupação sobre como se aprende, voltado para a pessoa" (MAYER, 2005, p. 9, tradução nossa), dessa forma, determina limites para a utilização das ferramentas tecnológicas em prol da aprendizagem. Na maioria das vezes, no processo de ensino e aprendizagem, as tecnologias são aplicadas sem um estudo prévio sobre as suas contribuições como ferramenta de ensino. Entretanto, utilizando-se dos princípios da TCAM, podemos acrescentar qualidades instrucionais aos materiais didáticos multimídias, além de buscar novas formas de ensinar. De acordo com Mayer (2005, p. 6, tradução nossa), "o que é necessário é uma base 
de pesquisa que compreenda como as pessoas aprendem através de palavras e imagens e em como desenvolver uma instrução multimídia que promova o aprendizado".

Essa teoria enfatiza os meios pelos quais as informações são acionadas no processo de cognição. Primeiramente, se baseia na teoria dos duplos canais de entrada das informações (PAIVIO, 1986) e no fato de que nossa capacidade de processamento cognitivo é ativa e limitada (BADDELEY, 1986, 1999). Após a entrada, pelos diferentes canais sensoriais, as informações são encaminhadas para a memória operacional (BADDELEY, 2000), e daí para a memória de longo prazo. Durante a recepção no processamento e passagem das informações da memória operacional para a memória de longo prazo, ocorrem seleções e integrações da informação instrucional que correspondem ao cerne da TCAM.

Mensagens instrucionais multimídia, elaboradas com base no mecanismo de como a mente humana recebe, processa e armazena as informações, são mais prováveis de levar a um aprendizado significativo (MAYER, 2005). Ainda de acordo com o autor, para que ocorra uma aprendizagem eficiente, seja de informações obtidas a partir de texto ou imagem, o aluno deve empregar cinco processos cognitivos: verbal;

1. Selecionar as palavras relevantes para o processamento na memória operacional

2. Selecionar imagens significativas para o processamento na memória operacional visual;

3. Organizar as palavras selecionadas em um modelo verbal;

4. Organizar as imagens selecionadas em um modelo visual;

5. Integrar as representações verbais e visuais com um conhecimento prévio.

Observa-se que, quando um material didático é construído de modo que o aluno utilize o canal visual para receber instruções de texto e de imagem simultaneamente, ocorre uma sobrecarrega da memória operacional (SWELLER, 2005). Isso dificulta a compreensão do conteúdo porque ambas as informações, texto e imagem, são processadas pelo mesmo canal. Por outro lado, em materiais instrucionais, os quais utilizam imagens acompanhadas de texto narrado, esses são processados por canais diferentes e alcançam melhores resultados na aprendizagem. Observa-se ainda que, como a memória operacional é de capacidade limitada, confeccionar materiais didáticos que não ultrapassem essa capacidade soma para facilitar a aprendizagem.

\section{Os princípios do planejamento de material multimídia}

A TCAM permite a análise de diversas combinações de representações externas (texto, imagens, exposição teórica utilizando quadro-negro ou projetor multimídia, vídeos, animações, cartazes, e outros recursos de apresentação do conteúdo) para indicar se essas são eficazes na aprendizagem. A partir dessa análise, são caracterizados efeitos positivos e negativos que são apresentados na forma de princípios da TCAM. Alguns princípios positivos são: modalidade, sinalização, contiguidade, coerência, segmentação e antecipação. Um princípio negativo é o da redundância.

Nesta pesquisa, optou-se por utilizar alguns desses princípios como parâmetros para a avaliação dos OAs, uma vez que esses priorizam a eliminação de sobrecarga cognitiva dos materiais multimídia. A seguir, descreveremos os sete princípios da TCAM, utilizados neste trabalho, para a avaliação dos OAs sobre o sistema digestório. 
- Princípio da modalidade: diz-se que alunos aprendem com maior facilidade se, em uma apresentação multimídia, as imagens são apresentadas junto com o texto narrado (MAYER, 2005). Como visto anteriormente, os dois principais canais sensoriais são: o visual e o auditivo. Se apresentarmos texto narrado, a informação entrará pelo canal auditivo, enquanto a informação da imagem entrará pelo canal visual, não ocorrendo sobreposição da informação em um mesmo canal.

- Princípio da sinalização: segundo esse princípio, a aprendizagem é mais eficiente quando existem sinais ou pistas que indicam, no texto, o que deve ser analisado na imagem. $\mathrm{O}$ ato de direcionar a atenção do aluno leva-o a focar nos elementos importantes para os objetivos da lição e facilita a seleção e organização na memória operacional (MAYER, 2005). A ausência de tais sinalizações pode tornar a busca por informação demorada, excedendo os limites da memória operacional. Esses sinais podem ser diversos: a) números no texto e na imagem, indicando a etapa do processo; b) uso da cor, de tal forma que a cor da palavra seja correspondente a algum elemento da imagem; c) aumento da voz, pelo professor, ao explicar um determinado conteúdo, chamando a atenção para uma informação em particular; d) dar ênfase às palavraschave; e) destacar as informações mais importantes, sublinhadas ou em negrito, diferenciadas das demais informações presentes no material.

- Princípio da contiguidade: com base nesse princípio, a aprendizagem é favorecida quando palavras e imagens correspondentes são apresentadas próximas uma da outra na tela ou na página (contiguidade espacial) ou no tempo (contiguidade temporal). Assim, uma forma de reduzir o processamento supérfluo é colocar o texto verbal próximo à imagem que ele descreve, tanto geograficamente como cronologicamente (MAYER; ANDERSON, 1992). Quando texto e imagem estão integrados, o leitor não precisa usar seus recursos cognitivos para uma busca visual na página ou em páginas distantes, facilitando o armazenamento de informações na memória operacional e a conexão mental (MAYER, 2001).

- Princípio da segmentação: diz que a aprendizagem é facilitada quando uma mensagem de múltiplos meios é apresentada em segmentos ao invés de uma unidade contínua (MAYER, 2005). Assim, para imagens complexas, a sua apresentação em etapas facilita a aprendizagem.

- Princípio da antecipação: chamamos de antecipação a indicação de Mayer (2005), segundo a qual, o ideal é apresentar as partes principais do sistema e, somente depois, introduzir os detalhes.

- Princípio da coerência: diz que pessoas aprendem melhor por meio de mensagens multimídia quando são excluídos materiais estranhos, como palavras, sons ou imagens não relevantes para o assunto. Quanto mais simples e objetiva for a apresentação do conteúdo, mais livre ficará a memória operacional para processar um número maior de conhecimento. Com base nesse princípio, mensagens multimídia não devem incluir palavras, imagens e sons que não sejam diretamente relevantes ao objetivo da instrução.

- Princípio da redundância: corresponde a um princípio negativo. Diz que a ocorrência de repetições excessivas de informações em apresentações multimídia provoca uma sobrecarga cognitiva, pelo fato de a memória operacional processar um material instrucional que não adiciona contribuição na compreensão do conteúdo.

Para Vigotsky (1991), a relação do sujeito e objeto é sempre mediada por instrumentos. O sujeito não se relaciona diretamente com o objeto, pois, entre eles, existem instrumentos de mediação que permitem atingir o objeto, o que caracteriza a aprendizagem como mediada. 
Assim sendo, a concepção de aprendizagem que adotamos nesta pesquisa se dá com base nos princípios da TCAM e nos pressupostos de Vigotsky (1991) e seus seguidores, como Leontiev e Luria (1973). Estes afirmam que os processos psíquicos mudam no homem do mesmo modo como mudam os processos de sua atividade prática. Vale dizer que também aqueles são mediatizados. É exatamente pelo uso dos meios e pela relação mediada com as condições de existência que a atividade psíquica do homem se distingue, radicalmente, da atividade psíquica (LEONTIEV; LURIA, 1973). Ao tomarmos por base a concepção de Vigotsky de atividade mediada por instrumentos (externos ao plano mental) e signos (internos ao plano mental), entendemos que avaliar os OAs, a partir do atendimento aos princípios da TCAM, pode ser um dos indicadores de sua qualidade como ferramenta de mediação em atividades de ensino e aprendizagem.

\section{Metodologia}

Esta pesquisa é de natureza qualiquantitativa. Isso porque, em um primeiro momento, foi realizada no ambiente natural, tendo como foco os ambientes virtuais nos quais os objetos de aprendizagem encontravam-se disponíveis. Assim, inicialmente, foi realizada uma análise quantitativa em que se verificou, nos OAs selecionados, o atendimento (total ou parcial) ou não aos sete princípios da TCAM: modalidade, sinalização, contiguidade, coerência, segmentação, antecipação e redundância. Posteriormente, recorreu-se aos princípios interpretativos para analisar os recursos visuais e verbais disponibilizados pelos OAs e suas relações com os princípios da TCAM. A busca pelos OAs foi realizada em repositórios de acesso livre do Ministério da Educação (MEC): Portal do Professor, Banco Internacional de Objetos educacionais, sites da editora Ática, Instituições Acadêmicas como a Universidade Estadual de Campinas, a Intel-Educação e no Youtube. Este último, por ser muito utilizado pelos alunos como fonte de pesquisas. Selecionaram-se OAs de fácil acesso, livres de custos ao usuário final, apresentados em língua portuguesa (Brasil e Portugal), e adequados a alunos de nível médio. Optou-se por selecionar aqueles, inicialmente, mais atraentes e interessantes de serem trabalhados em sala de aula, não levando em consideração os aspectos pedagógicos. Considerou-se, nesse momento, sobretudo, a qualidade estética e, superficialmente, a qualidade do conteúdo.

Os OAs selecionados para esta pesquisa e seus respectivos links encontram-se listados no Quadro 1. O período de acesso dos OAs ocorreu de agosto a outubro de 2009. Vale ressaltar que a maioria dos OAs avaliados $(70 \%)$ se encontra, atualmente, disponível na World Wide Web.

\section{Resultados}

\section{Análise quantitativa}

Conforme os dados apresentados no Gráfico 1, em relação aos princípios da TCAM analisados nesta pesquisa, percebe-se que o único atendido, de forma satisfatória, em todos os OAs analisados, foi o princípio da contiguidade espacial. Identificou-se a transmissão de informações de forma redundante em dois dos OAs analisados: o OA de número 03 (Egestão) e o 
Quadro 1. Objetos de aprendizagem sobre o sistema digestório avaliados na pesquisa

\begin{tabular}{|c|c|c|}
\hline $\begin{array}{c}\text { Objeto de } \\
\text { aprendizagem }\end{array}$ & Disponível em (endereço eletrônico) & Fonte \\
\hline $\begin{array}{l}\text { 1. Sistema } \\
\text { digestório }\end{array}$ & $\begin{array}{l}\text { <http://www.aticaeducacional.com.br/htdocs/atividades/ } \\
\text { sist_dig/index.htm>. Acesso em: } 06 \text { ago. } 2014 \text {. }\end{array}$ & Editora Ática Educacional \\
\hline 2. Nutrição & $\begin{array}{l}\text { <http://www.bdc.ib.unicamp.br/bdc_uploads/materiais/ } \\
\text { versaoOnline/versaoOnline47_pt/versaoOnline47.swf>. } \\
\text { Acesso em: } 06 \text { ago. } 2014 .\end{array}$ & $\begin{array}{l}\text { Biblioteca Digital de } \\
\text { Ciências - Universidade } \\
\text { Estadual de Campinas } \\
\text { (Unicamp) }\end{array}$ \\
\hline 3. Egestão & $\begin{array}{l}\text { <http://www.skoool.pt/content/los/biology/egestion/launch. } \\
\text { html>. Acesso em: } 06 \text { ago. } 2014 \text {. }\end{array}$ & skooolTM Portugal \\
\hline $\begin{array}{l}\text { 4. Enzimas e } \\
\text { digestão }\end{array}$ & $\begin{array}{l}<\text { http://www.skoool.pt/content/los/biology/enzymes_ } \\
\text { digestion/launch.html>. Acesso em: } 06 \text { ago. } 2014 .\end{array}$ & skooolTM Portugal \\
\hline $\begin{array}{l}\text { 5. Funcionamento } \\
\text { do sistema } \\
\text { digestório }\end{array}$ & $\begin{array}{l}<\mathrm{http}: / / \text { www.youtube.com/ } \\
\text { watch?v=li1BqYbtqpU\&feature=relate>. Acesso em: } 06 \\
\text { ago. } 2014 .\end{array}$ & Luiz Kazan (Youtube) \\
\hline $\begin{array}{l}\text { 6. Sistema } \\
\text { digestivo }\end{array}$ & $\begin{array}{l}<\mathrm{http}: / / \text { www.youtube.com/ } \\
\text { watch?v=zDRHGISphdE\&feature=related>. Acesso em: } \\
06 \text { ago. de } 2009\end{array}$ & Youtube \\
\hline $\begin{array}{l}\text { 7. Como funciona o } \\
\text { sistema digestivo? }\end{array}$ & $\begin{array}{l}<\text { http://static.hsw.com.br/flash/digestive-system.swf } \\
\text { Acesso em: } 06 \text { ago. de } 2009 .\end{array}$ & Não identificada \\
\hline $\begin{array}{l}\text { 8. Sistema } \\
\text { digestório }\end{array}$ & $\begin{array}{l}\text { <http://objetoseducacionais2.mec.gov.br/handle/ } \\
\text { mec/3167>. Acesso em: } 06 \text { ago. } 2014 .\end{array}$ & $\begin{array}{l}\text { Banco Internacional de } \\
\text { Objetos Educacionais }\end{array}$ \\
\hline 9. Parede intestinal & $\begin{array}{l}<\text { http://objetoseducacionais2.mec.gov.br/handle/ } \\
\text { mec/3322>. Acesso em: } 06 \text { ago. } 2014 .\end{array}$ & $\begin{array}{l}\text { Banco Internacional de } \\
\text { Objetos Educacionais }\end{array}$ \\
\hline $\begin{array}{l}\text { 10. A digestão } \\
\text { começa na boca }\end{array}$ & $\begin{array}{l}\text { <http://video.google.com/videosearch?q=a+digest } \% \\
\text { C3\%A3o+come\%C3\%A7a+na+boca\&www_google_- } \\
\text { domain=www.google.com\&hl=pt-BR\&emb=0\&aq=o\#>. } \\
\text { Acesso em: } 06 \text { ago. de } 2009 .\end{array}$ & Youtube \\
\hline
\end{tabular}

Fonte: elaborado pelos autores a partir de dados da pesquisa.

de número 04 (Enzimas e digestão). Nesses OAs, observa-se a repetição da mesma informação nas formas de texto narrado e escrito, o que pode levar a uma sobrecarga cognitiva, pelo fato de a memória operacional processar um material instrucional que não acrescenta contribuição na compreensão do conteúdo.

O princípio da segmentação também foi em apenas um dos OAs, o de número 02 (dois) (Nutrição), no qual se detectou que a mensagem instrucional foi dividida em passos ou segmentos de aprendizagem, a fim de facilitar a compreensão.

O princípio da sinalização foi atendido de forma satisfatória em apenas quatro dos dez objetos analisados. Percebe-se, portanto, que o direcionamento da atenção do aluno para elementos importantes nos textos e nas imagens está ausente ou subutilizado no desenvolvimento da maioria desses OAs. 
Almeida, R. R. et al.

Todos os objetos atenderam ao princípio da coerência, ainda que, em 50\% dos casos, tenha sido apenas de forma parcial. Ao se ter a preocupação de retirar palavras ou sons que não agregam valor ao conteúdo ensinado, deixa-se o aprendiz livre para melhor usar sua capacidade cognitiva.

Gráfico 1. Avaliação dos OA a partir dos princípios da TCAM

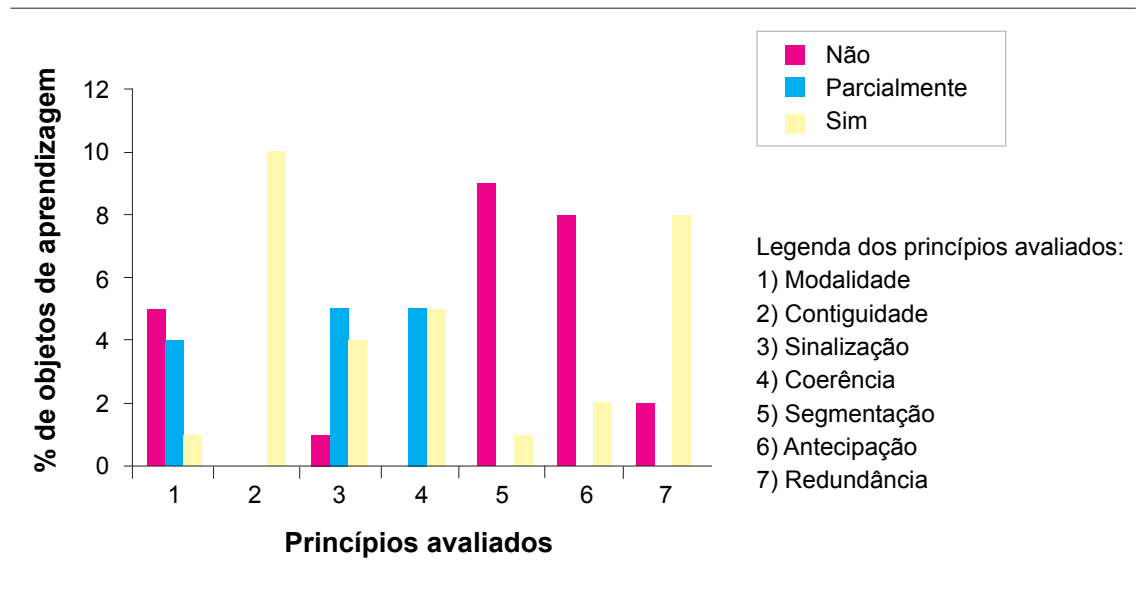

Fonte: elaborado pelos autores a partir de dados da pesquisa.

\section{Análise qualitativa}

OA 1 - Sistema digestório - Esse OA não atendeu ao princípio da modalidade, pois, apresenta imagens associadas a textos escritos em vez de narrados, ocorrendo a sobreposição de informação no canal visual. Apesar disso, ele atende bem ao princípio da sinalização, pois se observa, durante a sua exploração, a presença de elementos sinalizadores, como setas ou sinais luminosos que direcionam a atenção do aluno para as estruturas do Sistema digestório demonstradas. Observou-se que palavras e imagens correspondentes são apresentadas na mesma tela, ou seja, próximas uma da outra em vez de afastadas, conferindo atendimento ao princípio da contiguidade espacial. A presença de um volume adequado de informações na tela indica atendimento ao principio da coerência, mas imagens que julgamos serem supérfluas, como o "boneco" da Figura 1, são desnecessárias para a compreensão do conteúdo pelo contexto e pelas características do OA que estamos analisando. Dessa forma, identificamos, nesse ao, um atendimento parcial ao princípio da coerência. Quanto mais simples e objetiva for a apresentação de determinado assunto, maior a facilidade de processamento das informações por parte dos alunos. 
Figura 1. OA Sistema digestório

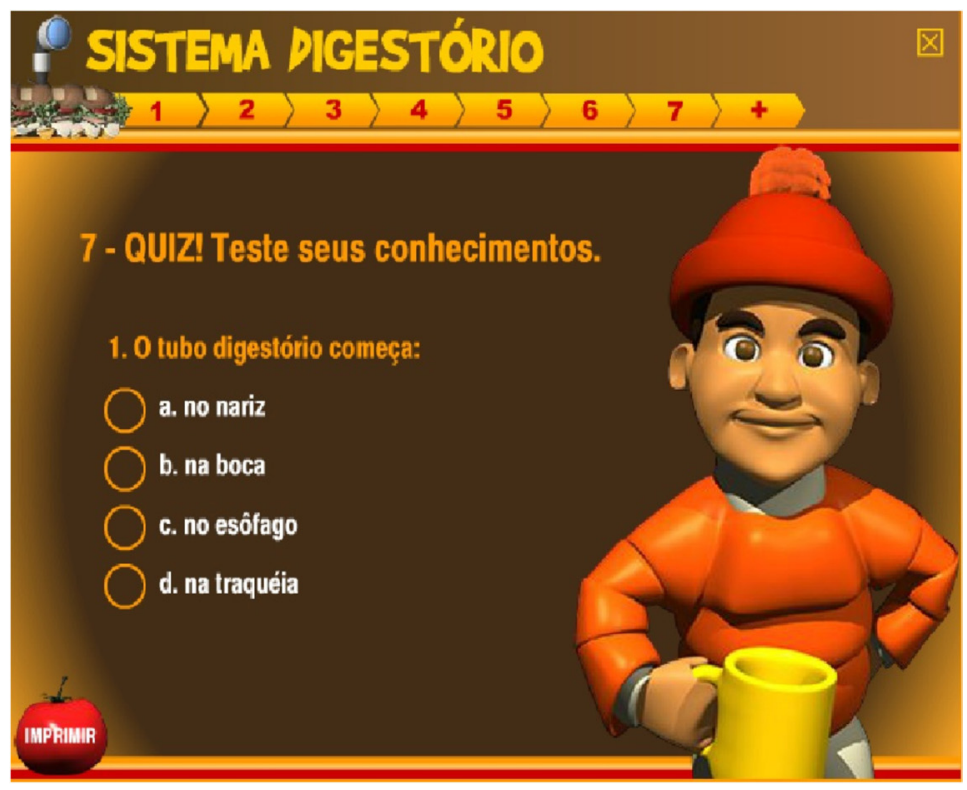

Fonte: Editora Fonte. Disponível em: <http://www.aticaeducacional.com.br/htdocs/ atividades/sist_dig/atv7.htm>. Acesso em: 06 ago. 2014.

A apresentação do Sistema digestório neste OA de forma contínua, não segmentada, indica o não-atendimento ao princípio da segmentação. Observou-se, também, um atendimento ao princípio da antecipação, no qual verifica-se que os produtores desse objeto se preocuparam em apresentar uma visão geral do Sistema Digestório, identificando as estruturas, para, só depois, apresentarem as estruturas associadas às suas funções. A informação passada apenas por meio do canal visual, não sendo sobreposta pelo canal auditivo, confere a esse recurso atendimento ao princípio da redundância.

OA 2 - Nutrição - Esse OA não atendeu ao princípio da modalidade, pois não apresentou imagens associadas aos textos narrados, mas aos escritos. Identificou-se atendimento ao princípio da sinalização por meio da presença de palavras destacadas em cores diferenciadas, sinalizando o que deve ser analisado na imagem; e de setas direcionando a atenção do leitor, o que evita a busca demorada de informação na imagem. A presença de imagens e palavras correspondentes, próximas uma da outra, ou seja, na mesma tela, reduziu o processamento supérfluo e atendeu ao princípio da contiguidade espacial. Não foi identificada, nesse OA, a presença de elementos estranhos, como sons, palavras ou imagens que não fossem relevantes para o assunto, atendendo, dessa forma, ao princípio da coerência.

Quando se divide o conteúdo, a carga cognitiva pode ser manejada decompondo-se a informação em passos ou segmentos de aprendizagem, ao invés de apresentá-lo em uma unidade contínua. Identificou-se, nesse OA, atendimento ao princípio da segmentação, uma vez que ocorreu uma divisão do conteúdo Sistema digestório, de carga cognitiva intrínseca elevada, em partes: digestão de carboidratos, proteínas e lipídios. Essa segmentação possibilita aos alunos aprenderem como se dá o processo digestivo de cada nutriente, para, posteriormente, relacioná-lo ao processo digestivo na sua totalidade. 
Não se observou uma apresentação com as partes principais do sistema digestório, para somente, depois, introduzir os detalhes. O conteúdo foi apresentado, desde o início, com riqueza de detalhes, o que indica um não-atendimento ao princípio da antecipação. O princípio da redundância foi atendido, considerando que não ocorreu a entrada da mesma informação pelos canais auditivos e visuais.

OA 3 - Egestão e OA 4 - Enzimas e digestão - Optou-se em avaliar esses dois OAs juntos por apresentarem características muito parecidas em relação à avaliação aqui proposta, e terem sido produzidos pela Intel Educação. A análise mostrou resultados semelhantes para quase todos os princípios, com exceção dos princípios da sinalização e da coerência. Nos dois OAs, verificou-se um atendimento parcial ao princípio da modalidade, pois apresentam, associada, às imagens, a informação auditiva (o que atende a esse princípio), mas, também, exibem a legenda daquilo que é falado (contrariando esse princípio). Além disso, a repetição da entrada da mesma informação, ao mesmo tempo pelos canais auditivo e visual, provoca uma sobrecarga cognitiva. Esses OAs não atenderam ao princípio da redundância, segundo o qual, quando se utiliza animação e narração, a aprendizagem é mais efetiva do que ao se utilizar animação, narração e texto.

Identificou-se, apenas no OA Egestão, atendimento ao princípio da sinalização por intermédio de ampliações feitas em partes específicas do Sistema Digestório, como o intestino grosso, chamando a atenção para informações que deveriam ser destacadas. Já no OA "Enzimas e digestão" não foi identificada, em momento algum, a presença de elementos sinalizadores. Sem sinalizações, a busca por informações poderá exceder os limites da memória operacional.

A apresentação do texto verbal próximo à imagem que ele descreve, tanto geograficamente, nesse caso, na mesma tela, indica atendimento ao princípio da contiguidade espacial (palavras e imagens correspondentes próximas uma da outra). Não se observou uma apresentação geral do conteúdo antes de se apresentarem os detalhes, isso indica um não-atendimento ao princípio da antecipação nos dois OAs.

Segundo Mayer (2005), na medida em que o material supérfluo é excluído, informações desnecessárias e/ou em excesso são retiradas da imagem. Assim, a aprendizagem tende a ocorrer de maneira mais simples e efetiva, princípio da coerência. Esse princípio foi atendido de forma parcial no Objeto "Egestão" e, totalmente, no Objeto "Enzimas e digestão".

Quanto ao principio da segmentação, não foi identificado atendimento ao mesmo, uma vez que as informações foram apresentadas de modo contínuo, em vez de segmentadas.

OA 5 - Funcionamento do Sistema Digestório - Este OA consiste em um vídeo que percorre todo o tubo digestivo com riqueza de detalhes, porém, o princípio da segmentação não foi atendido, uma vez que não se observou uma segmentação do conteúdo apresentado. $\mathrm{O}$ vídeo exibe as partes principais do processo digestório, para, só depois, inserir, de forma específica e mais aprofundada, a digestão de cada nutriente, como: carboidratos, proteínas e, por fim, lipídios. Tal estratégia conferiu atendimento ao princípio da antecipação. Também não foram identificadas repetições excessivas de informações nos canais visuais e auditivos que pudessem provocar uma sobrecarga cognitiva, atendendo, dessa forma, ao princípio da redundância.

A presença da informação verbal sobre a forma de legenda, no decorrer da apresentação do vídeo (Figura 2), sobrecarrega o canal visual e não atende ao princípio da modalidade. Caso a informação fosse passada em áudio, evitaria essa sobrecarga. 
Figura 2. Sistema digestório

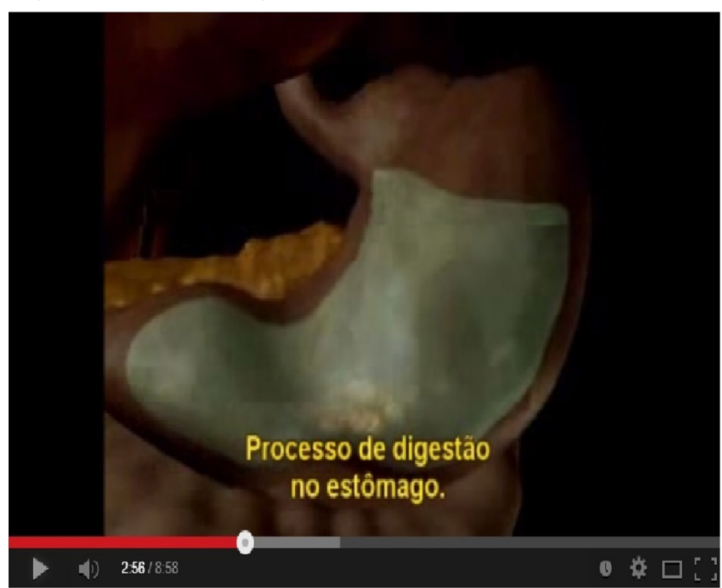

Fonte: Disponível em: <http://www.youtube.com/watch?v= li1BqYbtqpU\&feature=relate>. Acesso em: 06 ago. 2014.

Observou-se, ainda, a presença de poucos elementos sinalizadores que chamassem a atenção para eventos do processo digestivo demonstrados no vídeo, com apenas o uso de uma iluminação maior nas partes do sistema digestório que se queria destacar. Sendo assim, identificou-se um atendimento parcial ao princípio da sinalização. A utilização correta de elementos sinalizadores, de acordo com Mayer (2005), é importante para direcionar a atenção do aluno, e levá-lo a focar nos elementos mais importantes do conteúdo.

As palavras e imagens correspondentes aparecem próximas umas das outras durante a apresentação do vídeo, o que indica atendimento ao princípio da contiguidade espacial. No decorrer do vídeo foram identificados sons que não estão diretamente relacionados ao objetivo da instrução, atendendo dessa forma, parcialmente, ao principio da coerência. A música de fundo no vídeo pode causar uma sobrecarga cognitiva (SWELLER, 2005). A exclusão de material não instrucional pode desviar a atenção de informações importantes, romper o processo de organização do material, pois esse compete por recursos cognitivos na memória operacional (MAYER, 2001).

OA 6 - Sistema digestivo - O princípio da segmentação, que se relaciona com a divisão do conteúdo em etapas, para facilitar o trabalho da memória operacional, não foi identificado nesse OA. Ele atendeu parcialmente aos princípios da coerência, da sinalização e da modalidade. O princípio da Antecipação, quando primeiro apresentam-se as partes principais e, posteriormente, os detalhes do sistema, não foi atendido nesse OA. A informação foi passada apenas pelo canal visual, o que indicou um atendimento ao princípio de redundância. As palavras e imagens próximas umas das outras conferiram a esse $\mathrm{OA}$ atendimento ao princípio da contiguidade espacial.

OA 7 - Como funciona o sistema digestivo? - Nesse OA, o princípio da coerência foi obedecido, uma vez que se detectou simplicidade e objetividade na forma como o conteúdo foi apresentado, deixando a memória operacional mais livre para processar um número maior de conhecimentos. A apresentação do assunto de forma contínua, sem divisão em etapas, indica 
um não-atendimento ao princípio da segmentação. Não foi atendido, também, o princípio da antecipação, pois não se identificou uma apresentação geral do conteúdo antes de se apresentarem os detalhes. Não foi observada a presença de repetições excessivas de informações, o que propiciou o atendimento ao principio da redundância. A apresentação de texto e imagem, na mesma tela e de forma integrada, garantiu atendimento ao princípio da contiguidade espacial, pois, "o leitor não precisa usar seus recursos cognitivos para uma busca visual numa tela ou em telas distantes [...]” (MAYER, 2001, p. 81, tradução nossa).

A informação que acompanha a imagem é apresentada de forma escrita (Figura 3), não atendendo ao princípio da modalidade. Para que esse princípio fosse atendido de forma satisfatória, essa informação deveria ser narrada, assim, entraria pelo canal auditivo, e a informação da imagem, pelo canal visual, não sobrecarregando o canal visual. Identificaram-se, nesse OA, destaques nas imagens apresentadas (Figura 3), como pistas que direcionam a atenção do aluno, levando-o a focar nos elementos importantes para os objetivos da lição, o que facilita a seleção e organização na memória operacional, atendendo, dessa forma, ao principio da sinalização.

Figura 3. Como funciona o Sistema digestivo?

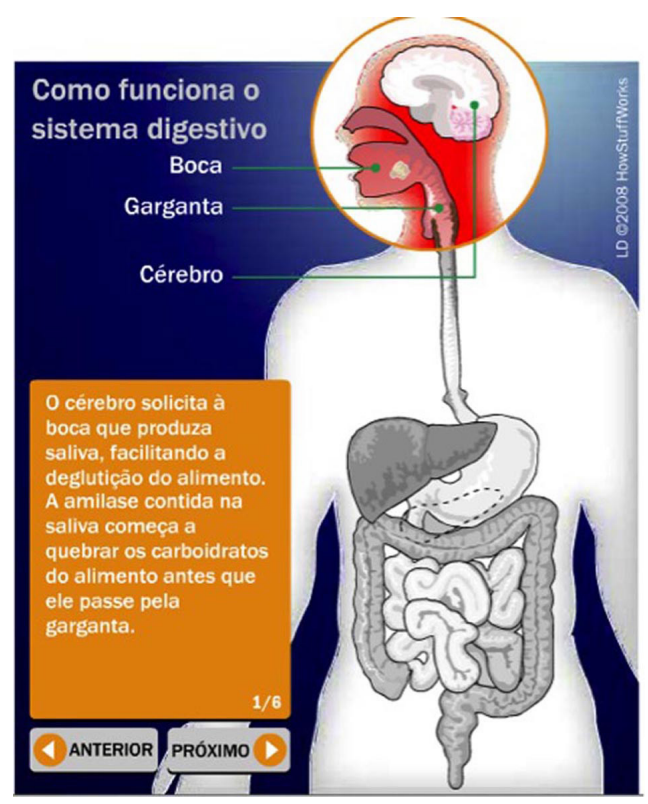

Fonte: Disponível em: <http://static.hsw.com.br/flash/digestive-system.swf>. Acesso em: 06 ago. 2009.

OA 8 - Sistema digestório - Este OA atendeu ao princípio da coerência, pois não se identificou presença de material supérfluo que pudesse distrair o aluno do foco do aprendizado. Entretanto, não atendeu ao princípio da segmentação, uma vez que a mensagem multimídia não foi apresentada em segmentos, mas por meio de uma unidade contínua. A presença de imagens e palavras relacionadas próximas umas das outras, na mesma tela, nesse OA, indicou atendimento 
ao princípio da contiguidade espacial que, segundo (MAYER, 2005), provoca uma redução no processamento supérfluo. Foi identificado atendimento parcial ao princípio da sinalização, visto que alguns sinais luminosos, mas de forma discreta, chamam a atenção para o que precisa ser analisado na imagem apresentada. Observou-se atendimento ao princípio da modalidade de forma parcial. Identificou-se atendimento ao princípio da redundância e não-atendimento ao princípio da antecipação neste $\mathrm{OA}$.

OA 9 - Parede celular - A transmissão da mensagem não dividida em passos ou segmentos, mas de forma contínua, conferiu a esse OA um não-atendimento ao princípio da segmentação. Contudo, identificou-se atendimento ao princípio da contiguidade espacial pela presença de palavras e imagens próximas umas das outras. De forma parcial, por meio de sinalizadores bastante discretos do que se deveria observar nas imagens, constatou-se atendimento ao princípio da sinalização. Esse OA também atendeu, de forma parcial, ao princípio da coerência, pela simplicidade e objetividade com que foi exposto o tema, não obstante, observou-se a presença de elementos estranhos no final do vídeo. Nesse OA não se identificou atendimento ao princípio da antecipação e da modalidade, por outro lado, o princípio da redundância foi atendido de forma satisfatória.

OA 10 - A digestão começa na boca - Quando dividimos o conteúdo em partes, facilitamos o trabalho da memória operacional. Com isso, a carga cognitiva de uma mensagem instrucional - de forma especial, aquelas de carga cognitiva intrínseca maior, como é o caso do sistema digestório - pode ser manobrada, dividindo-se a mensagem em passos ou segmentos de aprendizagem, ao invés de uma unidade ininterrupta. $\mathrm{O}$ atendimento ao princípio da segmentação, que prevê essas características em um material multimídia, não foi identificado durante a exploração desse OA.

Apesar disso, identificou-se atendimento ao princípio da contiguidade espacial ao se inserirem palavras e imagens correspondentes próximas umas das outras, fazendo com que os aprendizes não tenham de usar seus recursos cognitivos para procurá-las visualmente, podendo, ao mesmo tempo, guardar essas palavras e figuras na memória operacional, ao contrário do que aconteceria se elas estivessem distantes (MAYER, 2001, 2005). Foi identificado um atendimento parcial ao princípio da sinalização, pois se observou a presença de poucos sinalizadores que indicassem aquilo que deveria ser observado com maior atenção. Nesse OA, o princípio da antecipação não foi atendido; já o princípio da coerência foi atendido de forma parcial, e os princípios da modalidade e redundância, por sua vez, foram atendidos de forma satisfatória.

\section{Resumo dos resultados}

Os resultados da análise qualiquantitativa dos OAs selecionados, neste estudo, mostraram aqueles cujos princípios da TCAM foram melhor atendidos, sendo eles os de números: 01 (Sistema digestório), 02 (Nutrição) e 08 (Sistema Digestório). Esses OAs estão disponibilizados, respectivamente, pela Editora Ática Educacional, Biblioteca Digital de Ciências da Unicamp e pelo Banco Internacional de Objetos Educacionais do Ministério da Educação. Essas instituições basearam-se em parâmetros técnicos e cognitivos para a produção e divulgação desses OAs. Entretanto, o mesmo não ocorreu com o OA 09 (Parede intestinal), produzido pelo Centro de Ciências e Educação Superior a Distância do Estado do Rio de Janeiro (CECIERJ), e depositado no repositório do Banco Internacional de Objetos Educacionais. De modo geral, observou- 
Almeida, R. R. et al.

se que os OAs cujas produções não estão vinculadas a instituições educativas, como aqueles veiculados pelo Youtube, apresentam um atendimento menor aos princípios da TCAM, o que pode resultar, dependendo do objetivo da utilização, num comprometimento da aprendizagem.

\section{Considerações gerais}

Em relação aos OAs sobre o sistema digestório, avaliados nesta pesquisa com base nos princípios da TCAM, observamos que a maioria dos modelos instrucionais não levou em consideração os princípios dessa teoria na sua construção e produção. Esse dado é de particular interesse para as equipes envolvidas no processo de elaboração de OAs. Segundo a Teoria da Cognição Humana, materiais multimídias de valor instrucional ruim contribuem para uma ineficiência no processo de ensino-aprendizagem. Considerando que o uso de OAs em sala de aula é de grande importância, e que o tempo e as capacidades cognitivas do aluno são limitados, os planejadores e construtores de OAs, bem como os educadores, devem ficar atentos a esse problema.

Concluímos, pois, que os resultados obtidos no presente estudo indicam que, em relação ao conteúdo sistema digestório, existe a necessidade de que o planejamento e a construção de OAs sejam orientados por preceitos e critérios que visem tornar o uso dos recursos multimídia mais eficientes. Para tanto, são necessárias adaptações e correções que atendam aos princípios da TCAM satisfatoriamente. No entanto, salientamos que esse fato não contraindica o uso dos OAs aqui avaliados, mas reforça a necessidade e a importância dos professores avaliarem, fazerem escolhas e buscarem as melhores estratégias metodológicas para aperfeiçoar a utilização desses OAs no contexto da sala de aula.

\section{Agradecimentos}

Os autores agradecem à Coordenação de Aperfeiçoamento de Pessoal de Nível Superior (CAPES) pelo apoio recebido.

\section{Referências}

AMADOR, F.; CARNEIRO, M. H. O papel das imagens nos manuais escolares de ciências naturais do ensino básico: uma análise do conceito de evolução. Revista de Educação, Lisboa, v. 8, n. 2, p. 119-129, 1999.

BADDELEY, A. D. Working memory. Oxford: Oxford University Press, 1986.

Human memory. Oxford: Allyn \& Bacon. 1999.

. The episodic buffer: a new component of working memory? Trends in Cognitive Science,

Oxford, v. 4, n. 11, p. 417-423, 2000. 
BOFF, E.; REATEGUI, E. A importância do processo de avaliação de software educativo. In: SEMINÁRIO NACIONAL DE TECNOLOGIA NA EDUCAÇÃO, 2., 2005, Caxias do Sul. Anais... Disponível em: <http://ccet.ucs.br/dein/nase/snte2005.PDF>. Acesso em: 13 fev. 2012.

CAMPOS, G. H. B.; ROCHA, A. R. C. Avaliação da qualidade de software educacional. Em Aberto, Brasília, v. 12, n. 57, p. 32-45, mar. 1993.

KRESS, G.; VAN LEEUWEN, T. Reading images: the grammar of visual design. Routledge: London, 2001.

LEONTIEV, A. N.; LURIA, A. R. Le concezioni psicologiche li L. S.Vygotski. In: VYGOTSKY, L. S. Lo sviluppo psichico del bambino. Roma: Riuniti, 1973. p. 17-24.

MAYER, R. Multimedia learning. New York: Cambridge University Press, 2001.

MAYER, R. et al. The Cambridge handbook of multimedia learning. New York: Cambridge University Press, 2005.

MAYER, R.; ANDERSON, R. B. The in-structive animation: helping students build con-nections between words and pictures in multimedia learning. Journal of Educational Psychology, Washington, v. 84, p. 444-452, 1992.

PAIVIO, A. Mental representations: a dual coding approach. Oxford: Oxford University Press, 1986.

RENOVATO, R. D. et al. Significados e sentidos de saúde socializados por artefatos culturais: leituras das imagens de advertência nos maços de cigarro. Ciência \& Saúde Coletiva, Rio de Janeiro, v. 14, n. 1, p. 599-608, 2009. (Suplemento).

ROMERO, T. R. L.; ANDRADE, R. de; PIETROCOLA, M. Parâmetros para análise de roteiros de objetos de aprendizagem. In: SIMPÓSIO NACIONAL DE ENSINO DE FÍSICA, 18., 2009, Vitória. Anais... Disponível em: <http://www.sbf1.sbfisica.org.br/eventos/snef/xviii/sys/resumos/T0238-1. pdf>. Acesso em: 06 ago. 2014.

SANTOS, L. M. A.; TAROUCO, L. M. R. A importância do estudo da teoria da carga cognitiva em uma educação tecnológica. Novas Tecnologias na Educação, Porto Alegre, v. 5, n. 1, p. 1-11, jul. 2007.

SCHNOTZ, W.; LOWE, R. K. External and internal representations in multimedia learning. Learning and Instruction, Oxford, v. 13, n. 2, p. 117-123, 2003.

SOUZA, M. F. C.; PEQUENO, M. C.; CASTRO FILHO, J. A . FASE: uma ferramenta para automatização do processo de avaliação de software. In: CONGRESSO IBEROAMERICANO DE INFORMÁTICA EDUCATIVA, 8., 2006, San Jose. Anais... Disponível em: <http:/ /www.ufrgs.br/ niee/eventos/RIBIE/2006/ponencias/art082.pdf>. Acesso em: 06 ago. 2014.

SWELLER, J. Implications of cognitive load theory for multimedia learning. In: MAYER, R. E.

Cambridge handbook of multimedia learning. New York: Cambridge University Press, 2005. p. 19-30.

TAVARES, R. Aprendizagem significativa em um ambiente multimídia. Indivisa: Boletín de Estudios de Investigación, Monografía 8, Madrid, p. 551-561, 2007.

VIGOTSKY, L. Pensamento e linguagem. 3. ed. São Paulo: M. Fontes, 1991. 